\title{
EXPANSÃO DA EDUCAÇÃO SUPERIOR A DISTÂNCIA: A QUESTÃO DA INSTITUCIONALIZAÇÃO
}

\author{
EXPANSION OF DISTANCE HIGHER EDUCATION: THE ISSUE OF \\ INSTITUTIONALIZATION
}

Rosineide da SILVA ${ }^{1}$

Tânia Jucilene Vieira VILELA ${ }^{2}$

\section{Resumo:}

Este artigo trata da expansão da educação superior brasileira na modalidade a distância. A partir da aprovação da Lei $n^{\circ}$ 9.394/1996, o crescimento desta modalidade no Brasil tem sido relevante. Dessa forma, os cursos a distância em instituições públicas são ofertados por meio de Convênio entre o Ministério da Educação (MEC), Estados, Municípios e Universidades. O embasamento teórico está pautado em Lima (2013); Mercado (2011) e Preti (2009), com discussões relevantes para esse estudo acerca da educação a distância e sua institucionalização. Nesse cenário de expansão da modalidade EaD, nas instituições, estudos têm sido realizado sobre a questão da institucionalização.

Palavras Chave: Ensino Superior; Institucionalização; Educação a Distância.

\begin{abstract}
:
This article deals with the expansion of Brazilian higher education in the distance modality. Since the approval of Law No. 9,394 / 1996, the growth of this modality in Brazil has been relevant. Thus, distance learning courses in public institutions are offered through an agreement between the Ministry of Education (MEC), states, municipalities and universities. The theoretical basis is based on Lima (2013); Mercado (2011) and Preti (2009), with relevant discussions for this study about distance education and its institutionalization. In this scenario of expansion of the distance education modality, in institutions, studies have been conducted on the issue of institutionalization.
\end{abstract}

Keywords: Higher Education; Institutionalization; Distance Education.

\section{Introdução}

A partir da segunda metade do século XX houve um movimento visando o planejamento da educação brasileira com o intuito de atender as necessidades econômicas do governo e com isso foram organizados Planos Nacionais de Educação, priorizando os direitos

\footnotetext{
${ }^{1}$ rosineide.silva1981@gmail.com

2rrtrvilela4@gmail.com
} 


\section{HORIZONTES - REVISTA DE EDUCAÇÃO}

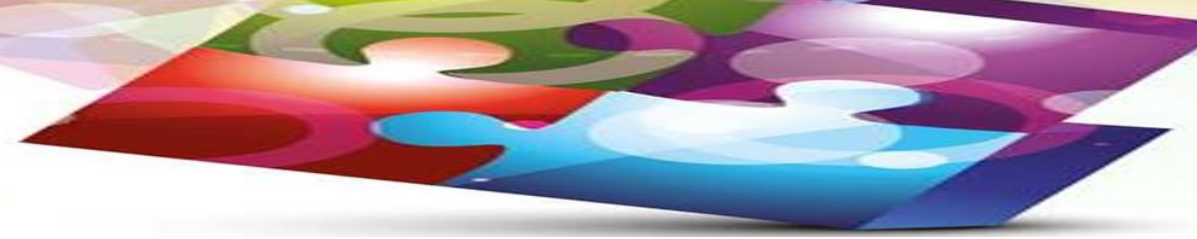

e a qualidade educacional (FONSECA, 2014). Evidentemente que a política brasileira tem sido direcionada para atender o crescimento socioeconômico e as demandas populacionais. A educação perpassa pela expectativa de expansão e qualidade, especialmente a educação superior a distância, quando uma das metas do Plano Nacional de Educação vigente, é ampliação no número de matrículas para 50\% da população jovem de 18 a 24 anos.

A educação superior promove a democratização, atendendo a demanda e proporcionando o aperfeiçoamento educacional, como pode ser observado no censo da educação superior ${ }^{3}$, referente ao quantitativo de matrículas realizadas nos últimos anos no País. Dessa forma, a expansão da educação a distância, promove reflexões politicas e sociais, objetivando a capacitação de um maior número de pessoas em todas as regiões brasileiras.

Nessa perspectiva relacionada a expansão e democratização, segundo Barros (2015, p.10) "a partir de 2003, observa-se que diversos programas foram implementados para colaborar com a chamada democratização da Educação Superior no país”.

Diante disso, a preocupação não é somente com relação a expansão, mas também com a qualidade da educação a ser ofertada. Conforme pontua Real (2008, p.26) “a não-qualidade do ensino superior estaria relacionada aos grandes temas que permearam o debate nacional nos últimos anos como expansão de cursos, vagas e instituições", além do financiamento dos cursos dentre outros fatores.

Dessa forma, a qualidade, de fato é uma preocupação a nível internacional e o debate tem se intensificado quando a questão está entre a quantidade e a qualidade. Segundo Oliveira (2005, p. 8), “a tensão entre qualidade e quantidade (acesso) tem sido o condicionador último da qualidade possível, ou, de outra forma, a quantidade (de escola) determina a qualidade (de educação) que se queira". Nesse ponto preocupa-se a expansão da EaD de forma acelerada, como tem mostrado os índices de matrículas do Censo da Educação Superior.

O Plano Nacional de Educação 2001-2010, foi pensado nesta modalidade como “ampliação de vagas e oferta em menor tempo" (ARRUDA \& ARRUDA, 2015, p. 324). Ao mesmo tempo em que se discute qualidade e quantidade, pensa-se em institucionalização dos cursos a distância nas instituições públicas.

No entanto, a expansão da EaD, em instituições públicas, via Sistema Universidade Aberta do Brasil (UAB), tem levado a reflexões no interior das universidades, sobre a questão da institucionalização de seus cursos e não somente criar novos cursos. Posto isso, percebe-se 


\section{HORIZONTES - REVISTA DE EDUCAÇÃO}

e-ISSN: $2318-1540$

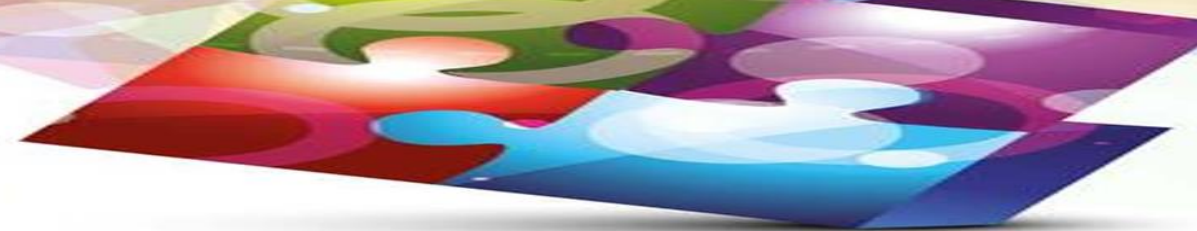

que a educação no ensino superior a distância tem obtido resultados significativos para o acesso e diversidade de cursos, ofertados para a população, pois a demanda no mercado de trabalho exige mão de obra qualificada e flexibilidade de horário para os estudos.

Nesse estudo, a metodologia está embasada na pesquisa bibliográfica, ou seja, através de estudos sobre o tema abordado que envolve a expansão da educação a distância no ensino superior e reflexões que versam sobre a institucionalização da modalidade no País, trazendo um olhar significativo entre políticas públicas educacionais.

O principal objetivo da pesquisa é refletir sobre a temática inovadora, abordada acima e suas nuanças aliadas às discussões para a melhoria e qualidade do ensino.

O trabalho esta embasado no referencial teórico dos seguintes autores: Lima (2013); Mercado (2011) e Preti (2009), dentre outros, que trarão pontos relevantes para este estudo acerca da educação brasileira, a modalidade a distância, a institucionalização e as políticas públicas no ensino superior.

Ao considerar que a educação tem passado por evoluções relevantes, analisa-se que sua melhoria no âmbito das políticas públicas, tem sido de grande valia ao ensino superior. Portanto, espera-se com este trabalho demonstrar resultados explanados sobre os pontos citados e concluir, mesmo de forma parcial, sobre a pertinência de mais estudos com essa temática voltada para a EaD e sua institucionalização.

\section{I - EXPANSÃO DA EDUCAÇÃO SUPERIOR A DISTÂNCIA}

A expansão da educação brasileira de forma presencial e a distância desde o século XX, meados dos anos 1990, tem sido tema de certa relevância em todos os níveis especialmente no ensino superior. Com o advento da Lei $n^{\circ}$. 9.394/1996 (LDB), foi reforçada a questão da diplomação em diferentes áreas do conhecimento nos cursos de graduação, pós-graduação e inclusive em cursos sequenciais. Em seu artigo 80, é enfatizado o incentivo do poder público no ensino a distância a ser oferecida por instituições de ensino superior, credenciadas pela União.

Evidentemente que a LDB proporcionou um avanço no número de instituições tanto públicas quanto privadas na oferta de cursos superiores. As universidades nos últimos anos tiveram considerável expansão em inovação e desenvolvimento econômico, fato destacado no campo das ciências e tecnologia como parte da política educacional do País (SERRA \& ROLIM, 2010). 


\section{HORIZONTES - REVISTA DE EDUCAÇÃOO}

e-ISSN: 2318-1540

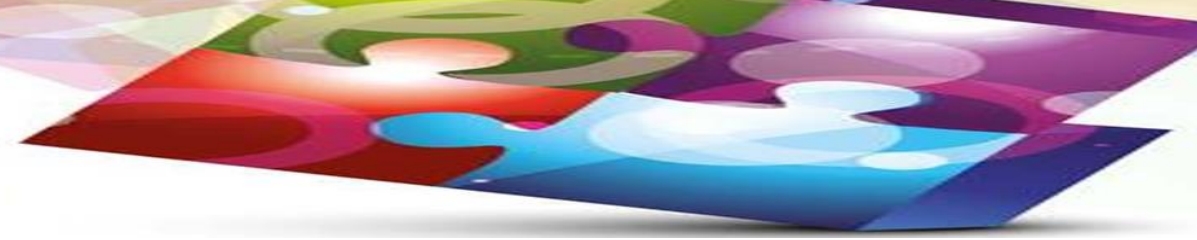

A política de expansão educacional geralmente vem acompanhada da democratização ao acesso, a permanência e a interiorização da educação superior, possibilitando a distribuição de vagas de forma justa e acessível a todas as camadas da população (RISTOFF, 2011). Segundo Dourado (2011, p.55):

A educação superior no Brasil, fortemente marcada por arranjos institucionais diversos, desde a sua institucionalização foi permeada por embates, no que concerne a sua dimensão, lógica e dinâmica organizativas, o que acarretou uma implementação tardia da organização acadêmica por meio da criação de universidades.

O autor destaca, ainda, que a expansão educacional tem dois lados, sendo um por meio de instituições privadas como forma isoladas e de outro, políticas intercessoras no âmbito das universidades "especialmente as públicas e parte das confessionais que, se de um lado redimensionam seus processos de organização e gestão por meio de maior qualificação do quadro docente" (DOURADO, 2011, p. 58).

Conforme destaca Giolo (2010), a expansão da educação superior brasileira movida pela quantidade de oferta em cursos, despertou a concorrência das instituições no sentido de atrair um quantitativo maior de alunos. E nesse intuito a educação a distância tornou-se de fato relevante, especialmente quando o quesito apresentado era a flexibilidade.

O Decreto $n^{\circ} 5.622 / 2005$ (BRASIL, 2005), reconheceu de forma oficial o ensino na modalidade a distância, corroborando para crescimento do ensino com a prerrogativa de capacitação de professores na educação básica e também superior (MUGNOL, 2009).

No ano seguinte, a Coordenadoria de Aperfeiçoamento de Pessoal de Ensino Superior (CAPES/MEC), instituiu a UAB, por meio do Decreto $\mathrm{n}^{\circ} .5 .800$ de 08 de junho de 2006 (BRASIL, 2006), com a finalidade de expandir e interiorizar nacionalmente cursos e programas de educação superior. A UAB estimula a parceria entre a União, Estados e os Municípios com as Instituições de Ensino Superior ${ }^{4}$. Este Decreto, segundo Arruda e Arruda (2015, p. 331):

Indica ainda que a CAPES fomentará a oferta emergencial de cursos de licenciatura e de cursos ou programas especiais dirigidos a docentes que atuam há pelo menos três anos, no âmbito de uma política nacional de formação de professores da educação básica. 


\section{HORIZONTES - REVISTA DE EDUCAÇÃOO}

e-ISSN: 2318-1540

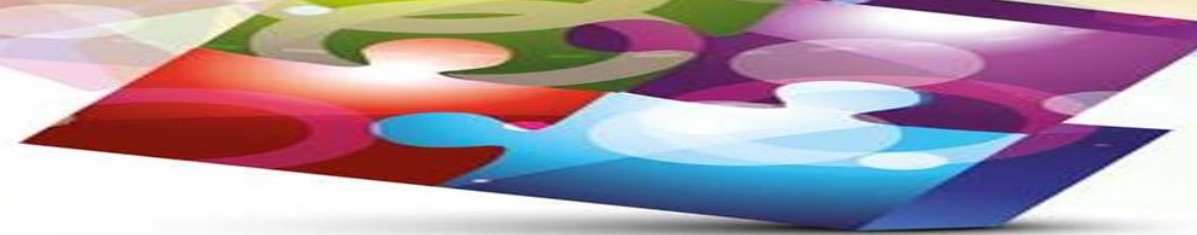

Neste cenário expansionista, o Plano Nacional de Educação (PNE) 2014-20245 , em sua Meta 12 destaca a necessidade de elevar a taxa bruta de matrículas na educação superior para $50 \%$ e a taxa líquida para $33 \%$ da população de 18 a 24 anos, e na Estratégia 12.20 esclarece que são para cursos presenciais e a distância.

Desse modo, diversas Instituições se dispuseram a investir no campo educacional dessa modalidade. Contudo, para oferecimento dos cursos na modalidade a distância, o primeiro passo das instituições é o seu credenciamento junto ao Ministério da Educação (MEC). De acordo com a Portaria Normativa n ${ }^{\circ}$ 11/2017/MEC (BRASIL, 2017), o credenciamento permite a oferta de cursos de graduação e pós-graduação lato sensu a distância.

$\mathrm{A} \mathrm{EaD}$, dado o ritmo acelerado do seu crescimento, tornou-se um campo propício para debates tanto no âmbito público quanto no privado, visando o reconhecimento dessa modalidade na formação de professores e na parte pedagógica (FARIA, 2011). Essa modalidade tem crescido de forma acelerada e isso traz questionamentos de como desenvolver a forma didática nesse meio tão dinâmico.

No entanto, com a prerrogativa da aceleração educacional e capacitação em maior quantidade, não se trata de tentar resolver tudo com o ensino a distância, mas empregar esse conhecimento como forma de educação flexível com qualidade (COSTA, 2009). Posto isso, não seria somente dar acesso a educação de forma descompassada, mas pensar como forma de agregar com a responsabilidade de apresentar um ensino de forma mais democrática, com quantidade e qualidade de ensino.

Consequentemente, há de considerar que a expansão precisa ser de forma consciente e legitimada e as "políticas públicas para a expansão e desenvolvimento da EaD como modalidade de educação já são realidade” (NASCIMENTO; VIEIRA, 2016, p. 32).

Evidentemente que não tem como expandir sem recursos financeiros apropriados pois, “à medida que a expansão pela $\mathrm{EaD}$ se dá por mecanismos de financiamento frágeis, bem como de contratação de profissionais da educação por meio de bolsas de estudo, a modalidade de EaD torna-se significativamente precária (ARRUDA; ARRUDA, 2015, p. 330) ”. Essa forma de contratação tem se apresentado como o grande gargalo para resolver a questão da institucionalização dos cursos ofertados a distância, nas universidades publicas federais. 
Conforme aponta Lobo (2011), o orçamento da UAB está condicionado aos recursos do Governo Federal, e caso venha acontecer percalços no repasse é provável que comprometa toda uma política articulada com o intuito de democratização e redução de dissemelhanças.

Com esse histórico e a evidente relevância da temática, efetuou-se um levantamento preliminar em diversas vertentes de pesquisa do País para fundamentar a questão da educação a distância e sua institucionalização no âmbito das Instituições de Ensino Superior. Conforme especifica Cellard (2008), não basta apenas fazer citações é de fundamental importância conhecer a procedência da informação disponibilizada, pois será a qualidade desta fonte que dará profundidade a análise efetuada. É nesse contexto que aborda-se a seguir a temática da institucionalização da educação a distância.

\section{II - A QUESTÃO DA INSTITUCIONALIZAÇÃO DA EaD}

Após anos de cursos ofertados nas instituições em uma parceria tripartite ${ }^{6}$, na modalidade a distância, ultimamente tem havido um interesse na abordagem da institucionalização. Importante salientar também, que a alavancagem no campo das tecnologias e comunicação, foram prioritários para consumação da modalidade no interior das instituições de ensino superior.

De acordo com Melo (2016, p. 12), a institucionalização é o "processo por meio do qual a Educação a Distância, hoje ofertada com aporte do programa Universidade Aberta do Brasil, passaria a ser não mais um programa do Governo", após todo o processo os cursos seriam parte da Universidade, com a mesma estrutura organizacional presente nos cursos presenciais.

Conforme estudos de Preti (2009), a nível internacional, há países que já se adiantaram nessa questão e resolverem institucionalizar os programas de educação a distância. No entanto, a nível nacional, o tema ainda carece de discussões pois a temática é capaz de alterar o paradigma no âmbito das universidades.

Para Alonso (2012, p. 1322):

Institucionalização da EaD em nosso país consolida a lógica da expansão nivelando ofertas que seriam diferentes em razão da natureza das instituições (se públicas ou privadas, universidades ou não), mas equalizadas quando da

6 Convênio celebrado entre a União, Instituições Públicas de Ensino Superior e Municípios ou Estados ou o Distrito Federal 


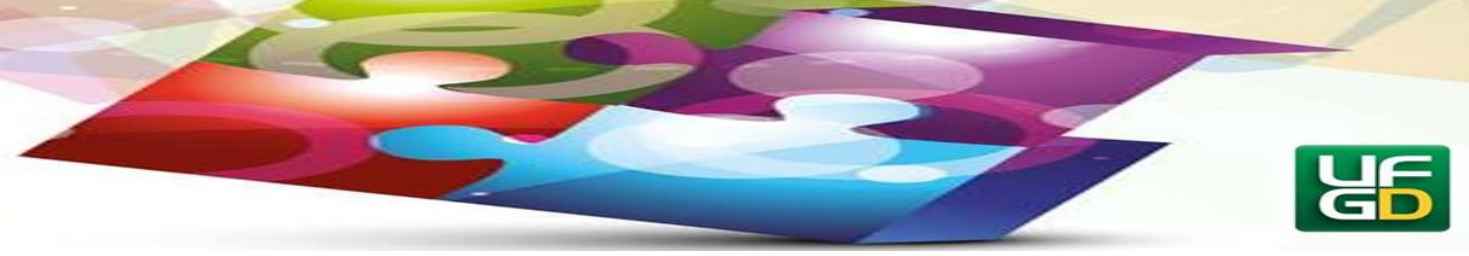

organização de seus sistemas, considerando os elementos/itens postos como os particulares para a modalidade.

De acordo com a citação, a institucionalização seria a forma de legitimação dos cursos no interior das Instituições. A educação a distância é uma política que teve suas discussões no âmbito das universidades, perpassou setores do Governo e fez parte de uma agenda para sua implementação. Dessa forma e de acordo com Silva (2013, p. 28):

Para uma política ser transformada em política pública e institucionalizada é preciso a participação dos atores envolvidos para não ser formatada por poucas mãos onde as preferências governamentais não traduzam as necessidades de um sistema de educação que propicie a formação de uma identidade nacional, mas que seja articulada com as demandas locais.

O pensar e formular sobre as políticas públicas e questões que envolvem a institucionalização vão demandar uma organização muito maior para que possa ser implementada, e assim deixar claro que isso acontece com base nas demandas locais.

Segundo Nascimento e Vieira (2016, p. 311), se considerarmos que a educação a distância despontou como algo emergente observa-se:

Que se encontra em fase de discussão na esfera acadêmica, é necessário que haja uma compreensão de como incorporar práticas, procedimentos, ações, políticas e diretrizes que estejam em consonância com a evolução das práticas difundidas nas IES, levando-se em consideração a atual dinâmica da sociedade contemporânea.

A temática em tela é considerado assunto controverso, porém de natureza contemporânea nas universidades públicas dado as resistências encontradas, principalmente no quesito referente a recursos financeiros (PRETI, 2009). Segundo o autor, muito se tem questionado do porque institucionalizar a modalidade nos interior de instituições estabilizadas com seus cursos presenciais. De acordo com Lima (2013, p. 54):

Institucionalizar uma prática, muitas vezes, exige que as organizações modifiquem suas estruturas de recompensa, políticas e do meio ambiente. No entanto, para qualquer inovação dada, diferentes aspectos da organização podem precisar ser modificadas a fim de assegurar o poder de permanência e seja rotinizado.

Abordando pelo lado da legitimação, o entendimento pode ser um tanto relevante quando ao institucionalizar, todas as normas e regulamentos aplicados a modalidade presencial seriam extensivas aos cursos a distância configurando uma formalização. Portanto, o processo 


\section{HORIZONTES - REVISTA DE EDUCAÇÃOO}

e-ISSN: 2318-1540

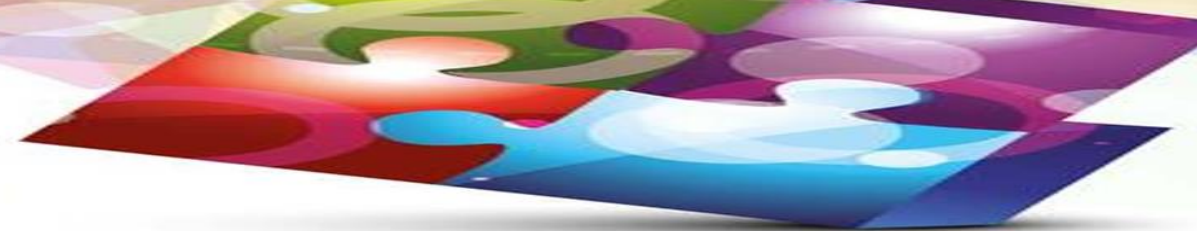

é relativamente complexo e iniciativo, carece de maiores investigações e fundamentações para ser de fato finalizado.

Isto posto, percebe-se nessas reflexões que o ensino superior a distância vem acontecendo de forma gradativa em sua expansão. Não se tem uma estimativa negativa sobre essa modalidade de ensino, mas sim, de um aumento relevante em termos de expansão e, muitas políticas públicas educacionais a serem pensadas, implementadas e efetivadas em nosso país.

No que se refere a institucionalização conforme pesquisas de Kesar e Sam (2013), está pautada mais na figura dos líderes das instituições, pois trata-se de questões políticas e administrativas destinadas a passar por fases, como a mobilização e implementação, que segundo as autoras, são consideradas fundamentais para reuniões, discussões e angariar recursos destinados a continuação e legitimação dos cursos ofertados, ou seja, a institucionalização.

\section{CONSIDERAÇÕES FINAIS}

A importância em desenvolver trabalhos voltados às políticas públicas na educação superior brasileira, transporta a questionamentos para um futuro mais promissor aos profissionais formados a cada ano no país. A preocupação de fato é com esse profissional, no sentido de obtenção de suporte para desenvolver um trabalho de qualidade em sua carreira e a aprendizagem possa ser elencada de forma social nesse ambiente educacional aos seus indivíduos.

Dessa forma, a pesquisa por meio bibliográfico fez com que refletisse mais sobre como esse processo enriquecedor, tanto para o ensino superior de modo geral, como para o crescimento e expansão da modalidade da educação a distância e a institucionalização nas instituições de ensino.

É relevante afirmar que as melhorias se conquistam com o tempo e não de forma imediata, mas que esse processo vai ser discutido e ainda, muitas demandas e inovações tecnológicas serão agregadas, como forma de compreender e enriquecer a qualidade da educação a distância. Mesmo sendo uma pesquisa somente de reflexões bibliográficas buscouse por meio de trabalhos já postos, refletir e obter conhecimentos significativos para amparar as situações postas em discussões.

A expansão da educação superior a distância no Brasil, vem com uma força relevante e muito se marca com todos os arranjos institucionais diversificados para a consequente 


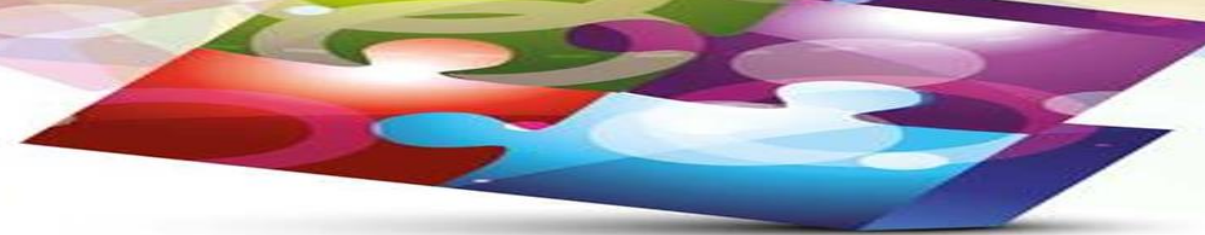

expansão. Com relação a institucionalização dos cursos já existentes no interior das universidades, as pesquisas e debates ainda continuam acontecendo nas instituições.

Evidentemente que a questão central, trata-se da dependência financeira para manutenção e continuação dos cursos ofertados e até o presente momento, depende do convênio com a UAB, visto que as instituições não têm recursos próprios para sustento.

No entanto, os embates precisam ser considerados, haja visto que não serão meramente pontuados, mais levados a uma amplitude de organizações e, as formas que cada instituição de ensino vai lidar com essas dimensões é que será o diferencial no campo das pesquisas.

\section{REFERÊNCIAS BIBLIOGRÁFICAS}

ALONSO, Kátia Morosov. A expansão do ensino superior no Brasil e a EaD: dinâmicas e lugares. Educação e Sociedade, Campinas, v. 31, n. 113, p. 1319-1335, 2010.

ARRUDA, Eucidio P.; ARRUDA, Durcelina Ereni Pimenta. Educação à Distância no Brasil: Políticas Públicas e Democratização do acesso ao Ensino Superior. Educação em Revista Belo Horizonte -MG, v.31, n.03, p. 321-338, jul/set 2015.

Disponível em:<http://www.scielo.br/pdf/edur/v31n3/1982-6621-edur-31-03-00321.pdf> acesso em. 20/02/2018.

BARROS, Aparecida da Silva Xavier. Expansão Da Educação Superior No Brasil: Limites E Possibilidades. Secretaria Estadual de Educação de Pernambuco, Programa de Educação Integral, Bezerros, PE., Brasil. Educação e Sociedade, Campinas, v. 36, nº 131, p. 361-390, abr.-jun., 2015. Disponível em: http://www.scielo.br/pdf/es/v36n131/1678-4626-es-36-13100361.pdf acesso em 21.02.2018.

BRASIL. Lei nº 9.394 de 20 de dezembro de 1996. Estabelece as Diretrizes e Bases da Educação Nacional.

BRASIL. Decreto n. 5.800 de 08 de junho de 2006 - Dispõe sobre o Sistema Universidade Aberta do Brasil - UAB.

BRASIL. Portaria n 1.369 de 07 de dezembro de 2010. Credenciar as Instituições Públicas de Educação Superior, vinculadas ao Sistema Universidade Aberta do Brasil. Diário Oficial [da] República Federativa do Brasil, Ministério da Educação, Seção I, p. 08, Brasília DF.

BRASIL. Lei n. 13.005 de 25 de junho de 2014. Aprova o Plano Nacional de Educação (2014-2024).

BRASIL. Portaria Normativa $n^{\circ} 11$ de 20 de junho de 2017. Estabelece normas para o credenciamento de instituições e a oferta de cursos superiores a distância, em 
conformidade com o Decreto no 9.057, de 25 de maio de 2017. D.O.U, seção 1, nº 117, p. 10 .

CELLARD, André. A análise documental. In: POUPART, Jean. A Pesquisa Qualitativa: enfoques epistemológicos e metodológicos. Petrópolis: Vozes, 2008, p. 295-316.

COSTA, Celso José da; PIMENTEL, Nara Maria. O sistema Universidade Aberta do Brasil na consolidação da oferta de cursos superiores a distância no Brasil. Revista Educação Temática Digital. Campinas, v. 10, n. 02, jun.2009.

DOURADO, Luiz Fernando. Políticas e gestão da educação superior no Brasil: múltiplas regulações e controle. Revista Brasileira de Política e Administração da Educação/RBPAE v.27, n.1, p. 53-65, jan./abr. 2011. Disponível em:

<http://www.seer.ufrgs.br/rbpae/article/viewFile/19967/11598> acesso em 15/02/2018.

FARIA. Juliana Guimarães. Gestão e Organização da Educação a Distância na

Universidade Federal de Goiás. Tese (Doutorado). Universidade Federal de Goiás (UFG), 2011, $277 f$.

FONSECA, Marília. O Planejamento Educacional no Brasil: Entre a Política de Estado e a Demanda Social. 2014. Disponível em:

<http://www.anpae.org.br/IBERO_AMERICANO_IV/GT5/GT5_Comunicacao/MariliaFonseca_GT5_res umo.pdf> acesso em 20/02/2018.

GIOLO, Jaime. Educação a Distância: Tensões Entre o Público e o Privado. Educação e Sociedade, Campinas, v. 31, n. 113, p. 1271-1298, out-dez. 2010. Disponível em <http://www.scielo.br/pdf/es/v31n113/12.pdf>. Acesso em 15/02/2018.

KEZAR, Adrianna; SAM, Cecile. Institutionalizing Equitable Policies and Practices for Contingent Faculty. The Journal of Higher Education, v. 84, n. 1, p. 56-87, jan./feb. 2013. Disponível em: https://muse.jhu.edu/article/494299/pdf. Acesso em: 05 mar. 2018. LIMA, Daniela da Costa Brito Pereira. Políticas Públicas de EaD no Ensino Superior: Uma Análise a partir das capacidades do Estado. Tese (doutorado) - Universidade Federal do Rio de Janeiro, Instituto de Economia - Programa de Pós-Graduação em Políticas Públicas, Estratégias e Desenvolvimento, 2013. 285 p. $31 \mathrm{~cm}$.

LOBO, Maria Eunice. Avaliação e Regulação da Educação da a Distância no Ensino Superior Brasileiro: um olhar sobre os processos de credenciamento institucional. Tese (Doutorado) - Pontifícia Universidade Católica de São Paulo (PUC-SP), 2011, 251f.

MELO, Alessandra Pessoa Coimbra de. Institucionalização da Educação a Distância na Universidade de Brasília (2005-2015). Tese (doutorado) - Universidade de Brasília (UNB). Biblioteca Depositária: BCEUNB, Brasília-DF. 2016, 237 f. MUGNOL, M. A EDUCAÇÃO A DISTÂNCIA NO BRASIL: conceitos e fundamentos Revista Diálogo Educ., Curitiba, v. 9, n. 27, p. 335-349, maio/ago. 2009. 


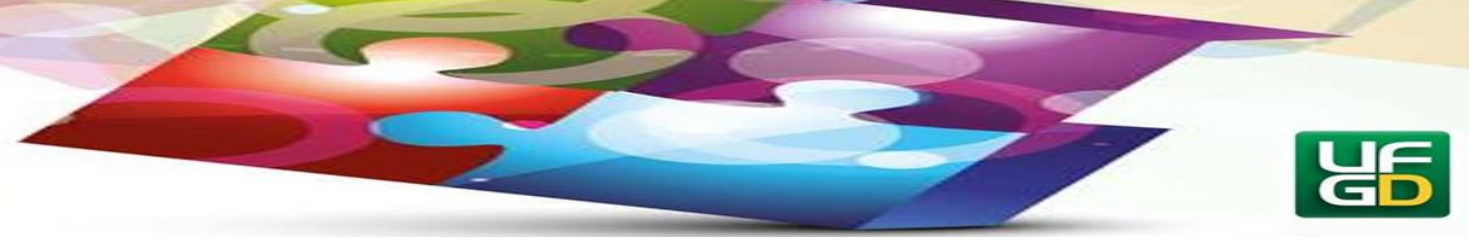

Universidade Federal. Ensaio: avaliação e Políticas Públicas em Educação, v.24, n. 91, p. 308-336, Rio de Janeiro, abr.jun. 2016. Disponível em <

http://www.scielo.br/pdf/ensaio/v24n91/1809-4465-ensaio-24-91-0308.pdf> acesso em .

OLIVEIRA, Romualdo Portela de \& ARAÚJO, Gilda Cardoso de. Qualidade do Ensino: uma nova dimensão da luta pelo direito à educação. Revista Brasileira de Educação, $n^{\circ}$. 28, Jan/fev/mar/abr, 2005.

PRETI, Oreste. Educação a distância: fundamentos e políticas. Cuiabá. EdUFMT, 2009, p. 131- 153.

REAL, Giselle Cristina Martins. Avaliação e qualidade no Ensino Superior: os impactos do período 1995-2002. Dourados, MS: UFGD, 2008.

RISTOFF, Dilvo Vinte e um anos de Educação Superior - Expansão e Democratização. Cadernos do GEA, n. 3, jan/jun, 2013. Disponível em <http://flacso.redelivre.org.br/files/2015/03/Caderno_GEA_N3.pdf> acesso em 02/02/2018.

ROLIM, Cassio; SERRA, Maurício. Universidade e Região: ser da região X estar na região. $7^{\circ}$ Congresso Ibérico de Estudos Africanos, Lisboa, 2010. Disponível em: < https://www.researchgate.net/profile/cassio_rolim/publication/266870391_ciea7_27_impacto_da_f ormacao_e_cooperacao_ao_nivel_do_ensino_superior_nas_dinamicas_africanas_contemporaneas/l inks/552c22c50cf2e089a3acc4b6/ciea7-27-impacto-da-formacao-e-cooperacao-ao-nivel-do-ensinosuperior-nas-dinamicas-africanas-contemporaneas.pdf> acesso em 20/12/2017.

SILVA, Gislene Magali da. O processo de Institucionalização da Educação a Distância no Instituto Federal de Educação, Ciência e Tecnologia de Tocantins - IFTO. Dissertação (Mestrado Profissional) - Universidade de Brasília (UNB), 178f. 2013.

Data do envio do trabalho: 05/08/2019

Aprovado em: 14/11/2019

Publicado em: 18/12/2019 